\title{
AFFECTIVITY IN ENVIRONMENTAL EDUCATION RESEARCH
}

Phillip Payne ${ }^{1}$

Cae Rodrigues ${ }^{2}$

Isabel Cristina de Moura Carvalho ${ }^{3}$

Laisa Maria Freire dos Santos ${ }^{4}$

Claudio Aguayo 5

Valeria Ghisloti Iared ${ }^{6}$

\begin{abstract}
In its ontological presuppositions, epistemological interests and methodological deliberations, critical theory of environmental education research (EER) is simultaneously scientific, normatively (and reflexively) critical, and non-idealistically practical. It is, therefore, a theory of practice, or praxis. Critical EE and its research aim for personal, social and ecological forms of justices achieved transformatively through the de and reconstruction of pedagogical, curriculum, policy and research practices that reconstitute various injustices. Missing from this reconstructive critique is the crucial role of aesthetics and the importance of affectivity in generating meaning about the agency of the researched by the researcher/actor. In this small scale self study of aesthetics and affectivity, we report on the deliberations of a workshop spread over two days about the aim of framing EER as a triad of environmental aesthetics environmental ethics - ecopolitics. We emphasize how sensuous ethnography in walking provided a methodological means within the mobility genre of interpretive research. We aim to generate meaning about the concept of ecosomaesthetics needed in a new language and images of environmental education. Some key images are included in the following text while others are referenced and available on-line (see footnote 7).
\end{abstract}

Key Words: Ecosomaesthetics. Praxis. Walking/sensuous ethnography.

\section{AFECTIVIDAD EN LA INVESTIGACIÓN EN EDUCACIÓN AMBIENTAL}

\section{Resumen}

En sus presuposiciones ontológicas, intereses epistemológicos y deliberaciones metodológicas, la teoría crítica en la investigación en educación ambiental (IEA) es a la vez científica, normativamente (y por reflejo) crítica y, de forma no-idealista, práctica. Es, por lo tanto, una teoría de la práctica, o praxis. La EA crítica, y su objetivo de investigación de formas personales, sociales y ecológicas de justicia han logrado transformativamente a través de la

\footnotetext{
${ }^{1}$ Environmental Educator and Research Methodologist and EdD in Critical Theory of Education. Professor, Faculty of Education, Monash University, Australia. <phillip.payne@ monash.edu>.

${ }^{2}$ Licenciado em Educação Física, Mestre e Doutor em Educação, Professor Adjunto, Universidade Federal de Sergipe, Brasil, Departamento de Educação Física. <caerodrigues@ufs.br>; <rodrigues.cae@gmail.com>. Corresponding author: Rua Niceu Dantas, n.99, ap.304, Atalaia, Aracaju, Sergipe. CEP: 49037-470. Telefone: (79) 991590052 .

${ }^{3}$ Pesquisadora do Programa de Pós-Graduação em Antropologia (PPGAS). isacrismoura @ gmail.com

${ }^{4}$ Bióloga, Mestra em Ciências e Doutora em Educação em Ciências e Saúde, Professora Adjunta, Universidade Federal do Rio de Janeiro, Brasil, Departamento de Ecologia. <laisa@biologia.ufrj.br>.

${ }^{5}$ Biologist, Learning Technologist and PhD in Sustainability Education. Research Officer, Centre for Learning and Teaching - Auckland University of Technology, New Zealand. < claudio.aguayo@aut.ac.nz>.

${ }^{6}$ Bióloga, Mestra em Ecologia e Recursos Naturais e Doutora em Ciências, Professora Adjunta, Universidade Federal do Paraná, Brasil, Setor Palotina, Departamento de Biodiversidade. <valeria.iared@ufpr.br>.
} 
reconstrucción de las prácticas pedagógicas, de curriculum, de política y de prácticas de investigación, que se reconstituyan diversas injusticias. Sin embargo, el papel crucial de la estética y la importancia de la afectividad en la generación del significado sobre la agencia del investigado por el investigador/actor han estado ausentes en esta crítica reconstructiva. En este autoestudio sobre la estética y la afectividad, de pequeña escala, informamos sobre las deliberaciones de un taller de dos días acerca de los objetivos de enmarcar la IEA como una tríada de estética ambiental - ética ambiental - ecopolítica. Hacemos hincapié en cómo la etnografía sensorial de caminar proporcionó un medio metodológico dentro del género de la movilidad de la investigación interpretativa para generar el significado del concepto de ecosomaesthetics (ecosomatoestética) como necesario en un nuevo lenguaje e imágenes de la educación ambiental. Algúnas imágenes claves están incluidas en el presente texto, mientras que otras están referenciadas y accesibles on-line (ver nota 7).

Palabras Clave: Ecosomatoestética. Praxis. Etnografía sensorial/del caminar.

\section{AFETIVIDADE EM PESQUISAS EM EDUCAÇÃO AMBIENTAL}

\section{Resumo}

Em suas pressuposições ontológicas, interesses epistemológicos e deliberações metodológicas, a teoria crítica na pesquisa em educação ambiental (PEA) é, simultaneamente, científica, normativamente (e reflexivamente) crítica e, de forma não idealista, prática. Desse modo, é uma teoria da prática, ou da práxis. A educação ambiental crítica e suas pesquisas objetivam formas pessoais, sociais e ecológicas de justiças alcançadas/conquistadas, transformativamente, pela desconstrução e reconstrução de práticas pedagógicas, de currículo, de elaboração de políticas e de pesquisa que reconstituem diversas injustiças. A estética e a afetividade são dimensões pouco presentes nessa reconstrução crítica. Contudo, ambas as dimensões são cruciais na geração de sentidos e agência dos ambientes e pessoas pesquisados. No presente autoestudo sobre estética e afetividade, realizado em pequena escala, reportamos sobre as deliberações de um workshop realizado durante dois dias, que teve como objetivo compreender a PEA na tríade estética ambiental - ética ambiental - ecopolítica. Enfatizamos como a etnografia sensorial do caminhar nos ofereceu uma visão metodológica, na perspectiva da mobilidade em pesquisas interpretativas, para a produção de significado sobre o conceito de ecosomaesthetics (ecosomaestética), necessário em uma nova linguagem e imagem de educação ambiental. Algumas imagens-chave foram incluídas neste texto, enquanto outras são referenciadas e estão disponíveis para visualização on-line ${ }^{7}$.

Palavras-chave: Ecosomaestética. Práxis. Etnografia sensorial/em movimento.

\footnotetext{
${ }^{7}$ Link de acesso e código QR para álbum de fotos on-line / Access link and QR code to online photo album / Enlace y código QR del álbum de fotos online: 〈https://drive.google.com/open?id=0BxwGYr3hZVWdZ1RoNVhyaHk3RGs>
} 


\section{Walking the talk}

One major gap in the theoretical and empirical development of environmental education research is the role of aesthetics and embodied place of environmental affectivity. This gap can be traced to the initial "framing" and conceptualization of the research purposes (on-line picture album Day 1 - Conceptualization - photo Conceptualization 2) and subsequent ways research problems are contextually posed (PAYNE, 2009), methodologies are experimented with, meaningful data are generated, interpretations are derived and represented, and findings about human-environment and culture-nature relations are legitimately proposed, or recommended. Filling this gap in research has important implications for environmentalizing critical pedagogy - namely, highlighting the environmental design of the social design of school curriculum and community programs, achieving the environmental sustainability of policies for sustainable development and, in general, the revaluing of environmental ethics and ecopolitics of education.

At philosophical and theoretical levels of framing environmental education research, we also develop the notion of ecosomaesthetics that informs inquiry into the lived experience of environmental interactions and relations (PAYNE, 2013). The prefix eco signifies a non anthropocentric, or ecocentric, disposition in inquiry. Soma, from the Greek, locates this disposition in the sentience of human being and actancies of non human bodies and things in nature and its various environments. Somaesthetics refers to the bodied generation of meanings and making of understanding. Ecosomaesthetics pedagogically integrates these different but overlapping concepts into, following Ted Toadvine's (2009) ecophenomenology, questions about what is the experience of nature? And what is the nature of experience? For environmental education that strives to be critical, Lesley Le Grange (2013) called for a "new language of environmental education". Ecosomaesthetics is part of that new language as its interpretation is embodied in an ecophenomenological disposition to inquiry we develop here in this study of aesthetics and affectivity.

Historically in the Anglo-speaking "North-West" and Portuguese-speaking "SouthLatin", critical environmental education researchers have developed important insights into and methodological approaches to the ethics and politics of their own and others' research efforts (ROBOTTOM; HART, 1993; GRÜN, 1996; JACOBI, 2003; 2005; RUSSELL; HART, 2003; HART, 2005; SATO; ISABEL, 2008; STEVENSON; 2013). The ethics and politics of environmental education are mostly on display in critical curriculum theory and pedagogical innovation (for example, FIEN, 1993; PAYNE, 1999; SORRENTINO, 2005; TOZONI-REIS, 2007; CARVALHO. 2008). Most recently, Payne's (2015) study of "slow ecopedagogy" with young Australian children in critical environmental education combines environmental and social aesthetics, ethics, and politics. Evidence of an empirical type about the value and efficacy of the various framings of research, curriculum, pedagogy and environmental learning are available (for example, HART; NOLAN, 1999; REID; SCOTT, 2006; RICKINSON; LUNDHOLM; HOPWOOD, 2009; CARVALHO. 2010).

Despite this normative progress in establishing an ethics and politics of environmental education, there are very few examples of research, inquiry and critique, or curriculum theory or pedagogical enactment where the centrality of human and social aesthetics and environmental aesthetics are emphasized. Very few empirical studies about "feelings" and emotions, or affectivity, of the researched and researcher are incorporated into the framing of the research problem, clarifying the questions posed relevant to the purposes of the study, elaborating the human and environmental qualities and characteristics of the research context or circumstances, explaining the methodological dispositions and intricacies of the research, and elucidating appropriate criteria for the ways in which the interpreted findings are to be represented and legitimized in the public domain. Notable exceptions to this major gap about aesthetics include some chapters in McKenzie et al's (2009) Fields of Green. That collection 
of essays aims to "restory" the discourse of environmental education by emphasizing the "sensuous", including stories about reanimation and revitalization, emotions and feeling, affect and the place of ecopoetics in environmental education and its research. Marin's (2008; MARIN; OLIVEIRA, 2005) focus on the contribution of "environmental perception" to aesthetics in education highlights how there is a human need for affectivity, nostalgia, and aesthetic sensibility. Carvalho and Steil (2013) have grappled with the "sacred" of the spiritual, environmental and educational experience of natural spaces.

Beyond these rare exceptions, the silence about an aesthetics of environmental education limits the field's aspirations and constrains its expectations. In particular, the invisibility of findings about the affectivities of participants (learners, teachers, guides, parents, bureaucrats, policy-makers, researchers) means that we can only speculate about the even more normatively powerful relationships of aesthetics-ethics-politics in environmental education research, theory and praxis. Both speculation and empirical insight are required about the role of aesthetics and place of affectivity if, indeed, environmental education is to holistically embrace the inter, cross and/or transdisciplinary formation of a needed socio-ecological theory of education; where such a theorization and new language for environmental education and its research reflects the need for practical value in the lives that theory purports to serve-praxis.

More specifically, at the $13^{\text {th }}$ Invitational Seminar on Research Development in Environmental Education held in Brazil in July, 2015 (on-line picture album Day 1 Conceptualization - photo Conceptualization 3), the six co-authors (on-line picture album Day 1 - Conceptualization - photo Conceptualization 4) contributing to this "reflection" about the praxis of our "aesthetics-ethics-politics" workshop also struggled with the more formidable, less or non anthropocentric question of the critical ecopedagogical relationship of environmental aesthetics-environmental ethics $\sim$ ecopolitics. The tilde $\sim$ is used to represent our hypothesis that those three dimensions are mutually constitutive. Indeed, that hypothesis, or theoretical assumption, now needs to be tested empirically in a wide range of research, curriculum/program, and pedagogical settings, with different populations in different socio ecological contexts, or geo cultural historical ecological "locations of knowledge" (CANAPARO, 2009).

We tested this hypothesis by "walking the talk" during the $13^{\text {th }}$ Seminar. Consistent with the praxis imperatives of critical theory and its aspirations for transformation, we took our indoor afternoon workshop "talking" session into the outdoors the next morning into the field on a four hour guided "walking" in the nearby Atlantic forest. 


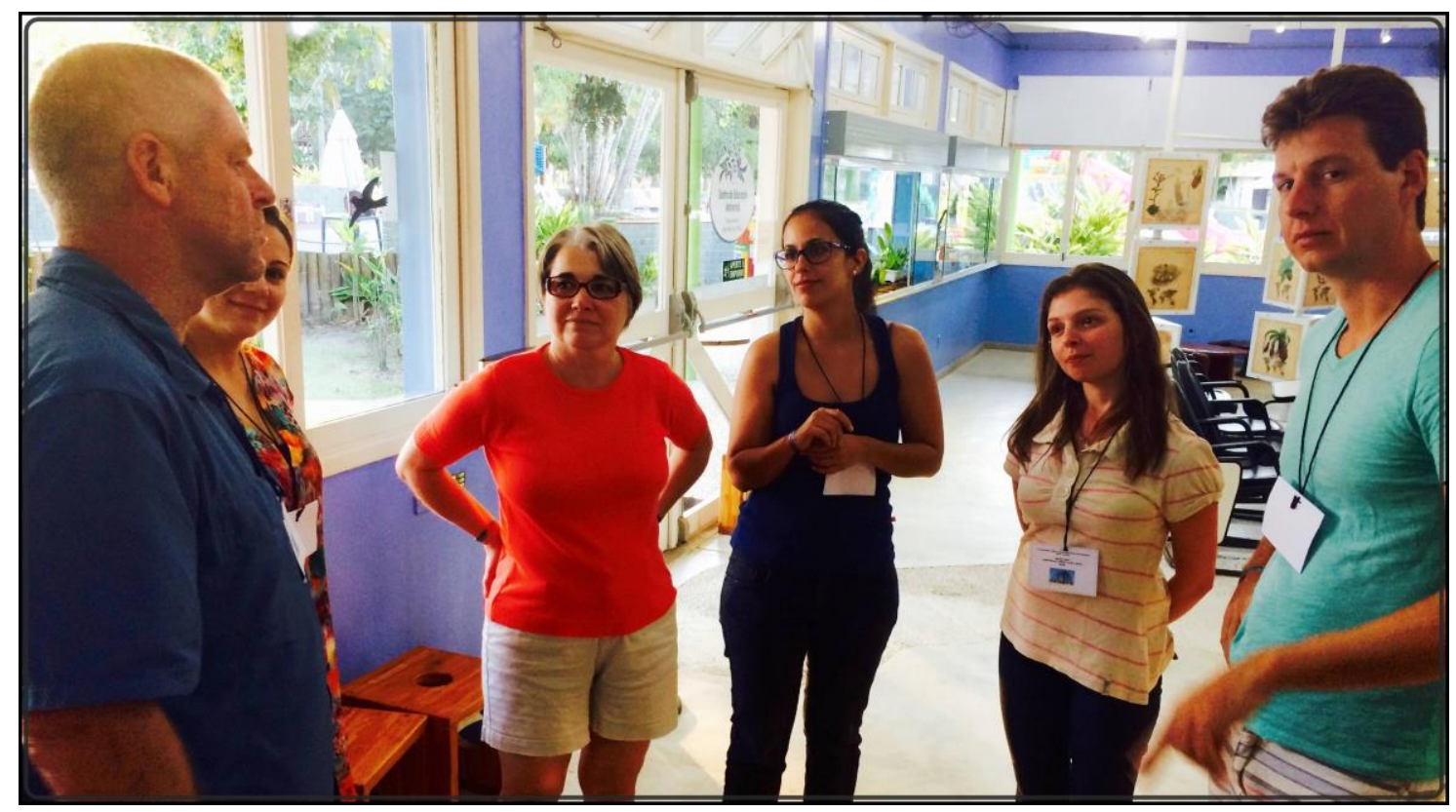

(Talking)

About twenty seminar participants on a warm sunny morning walked fairly slowly along a trail in a semi natural open space that meandered through a mangrove swamp, Atlantic Forest, across a rarely used railway track, past some old buildings, under power lines, next to a slow flowing stream with, following some recent rain, a rockpool fed by a small waterfall in which some excited participants sensuously/affectively "stepped without shoes" (PAYNE, 2014) and "dipped their toes" (PAYNE; WATTCHOW, 2009) with a swim in the cold, clear water.

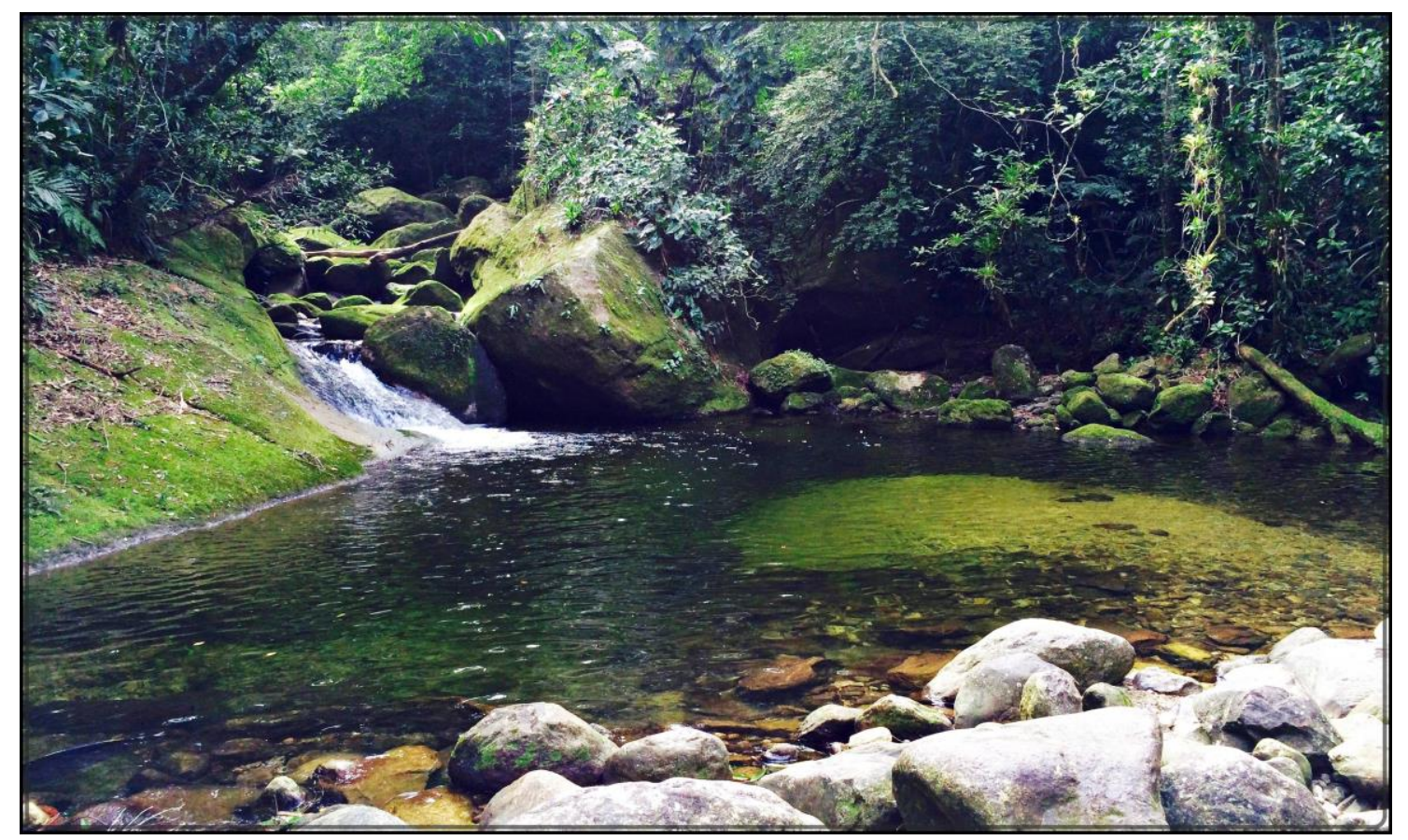

(Perceiving and sensing things)

This setting for our workshop "walking the talk", and the guiding/interpretation provided by two non workshop local experts "talking the walk", provided an illustrative social 
and geographical "context" for some basic research practice for us co-authors of "what is going on during the walk?".

The (eco)"pedagogy" of the guides, and the responses of the participants, could be observed (only) by us during the walking, talking, lunching and swimming. However, the twenty odd other workshop walkers were not the focus of our research practice as praxis. For the six of us, our earlier workshop "talking" indoors was restricted (by necessity due to time limits of the workshop) to discussing the meanings of "affectivity" as they, in turn, might be "ecologically epistemologically" (CARVALHO, 2014), (and methodologically) relevant to the current research projects in which we were involved. Our research practice during the walk, and in this collective and iterative writing and summary of the research practice, focused only on how some of us interpreted and translated into our own practices of conducting the sensuous walking ethnography. The extent to which some of the researchers/co-authors were praxically transformed in the activity and actions of research is our main interest.

More broadly, therefore, the workshop aimed at our collective "filling a gap" in the progressive development of critical environmental education research and the framing of research problems and formulation of questions, as well as opening up the task of methodological deliberation for researcher reflexivity. Methodologically, ethnographic approaches to inquiry using "sensuous" means (PINK, 2009), and mobility practices (FINCHAM; MCGUINESS; MURRAY, 2010) such as "doing through moving" (PAYNE, 2005) and "walking" (PAYNE, 2014; IARED; OLIVEIRA; PAYNE, 2016) and "ecomotricity" (RODRIGUES, 2009; 2015) are only now being incorporated into ("post")phenomenological framings of "post-critical" environmental education research (HART, 2005). More recently, Hart (2013) asked researchers "Can we see ourselves within our own terrain?". In this study, we seek to make very clear the "preconceptions" and "positionings" Hart calls for, as they have been contextualized in the indoor and outdoor components of our workshop.

Pre-reading (and, therefore, challenging of preconceptions) for the aesthetics-affectivity workshop included sections from Canaparo's (2009) critique of Latin America and its locations of knowledge; Jay's (2002) provocative account of the exclusion of somaesthetics from the democracy of knowledge; Pink's (2009) proposal for how to do sensory ethnography as a form of intervention; and Thrift's (2008) comprehensive review of the literature on "affect" within the spatialities of feeling where the impossibility of fully representing (in words, texts, discourses) "affectivity", "feeling" and "emotion" (or somaesthetics and aesthetics) is highlighted (see also, CARVALHO; STEIL, 2013).

In "walking the talk" of methodological experimentation in the three hour field trip outdoors, we sought to empirically "test" how that socio-environmental context - as "constructed" and "talked" by the two guides/experts and "experienced" by the novice participants - was amenable to ethnographic observation and might be practiced by members of our workshop while "walking/moving" through the semi-natural environment. That is, we reflexively understood how we were now conceptually $r e$ "positioned" as researchers during and after the walking experience.

Effectively, our "reflective practice" and reflexive writing of it here is a form of collegial "self study". This self-study of our practicing of walking the talk weaves its narrative representation through somewhat autoethnographic understandings and contributions to the seminar workshop. Our emphasis on the construction of the nature experience provided a focus point and participatory/experiential means through which the existing practices of environmental education research might be 'transformed'. Two of our workshop members (Laísa and Claudio) were not familiar with 'walking ethnography'. Valéria recently completed her $\mathrm{PhD}$ research that included a small scale case study of environmental aesthetics using a walking ethnography (IARED, 2015). Effectively, our collective task of 'walking the talk' as a 
way to progressively practice affectivity in the aesthetics of research constituted the praxis to bridge or repair the typical theory - practice divide of research.

The broad research question we respond to below in different ways was: "How, and in what ways, was the 'experience' of the environment/'nature' (in a modified Atlantic Forest) constructed (pedagogically by the interactions/communications/relations of the participants) as 'afforded' while moving/walking the Forest trail?". The specific question: "Where was (sensory) 'affectivity' presenced (and non presenced)?". Our precise task, combined here as self study, narrative and autoethnography, is to represent in the comfort of our respective "first" languages how we collectively and individually were "positioned" in this potentially transformative praxis.

Following Payne's (2009) alternative approach to framing critical environmental education research, outlined above, the remainder of this text moves through:

- Isabel provides a conceptualization of "aesthetics" and how it relates to "affect" ("affectio"; "affectus") and "perception" as they inform an aesthetic dimension of human experience where the affectivities of experience are subjectively meaningful to and, potentially, generative of an emergent notion of ecosomaesthetics as it might be made meaning of in social and environmental ethics and ecopolitics.

- Contextualization 1. Laísa and Claudio dialogically interpret and represent some key examples, or "outcomes" of how they were affectively and reflectively/rationally "transformed" as researchers practicing the previously unfamiliar walking/sensuous ethnography. For ethical reasons, their self representations of the transformations they felt, and now rationalize, are a form of self study. We do not attempt to represent how other participants (guides, walkers) felt or believed they were individually and collectively "constructed" by the field trip, perceived and sensed the environment, or responded to the guides/experts provision of local knowledge.

- Contextualization 2. Valéria interprets and represents some of her major observations of Laísa and Claudio's actions in practicing the walking ethnography in relation to the broad research question we investigated. Valéria's observations/representations of Laísa and Claudio's actions in practicing walking ethnography highlight some of the key rewards, prospects and challenges for research development for researchers interested in, intrigued by or already undertaking sensuous approaches to inquiry that incorporate aesthetics, somaesthetics and/or environmental aesthetics/preferences/affordances and ecosomaesthetics.

- Representation and legitimation. Cae's "case study" synthesis of the preceding sections emphasizes the ongoing quest and "what next?" in this interpretive/qualitative type environmental education research for greater "commensurability" (or internal coherence) (PAYNE, 2005) between: a) the purposes of "critical" environmental education research; b) the need for posing difficult research questions that are then supported by c) adequate concepts and conceptualizations, d) use of and experimentation with appropriate methodological deliberation and e) its creative development during the conduct of research mindful of its limitations and then $\mathrm{f}$ ) in the interpretation and (re)presentation of insightful but robust "findings" as the g) legitimate but tentative and partial "ends" of the a) initial purposes of the research task. 


\section{Bases conceituais para uma educação ético-estética}

Considerando que neste trabalho nos referimos a uma prática de educação ético-estética, é importante tecer algumas considerações sobre o que consideramos "estética" e os conceitos correlatos de afeto, afecção e percepção. Entendemos que uma educação ético-estética é aquela em que predomina a dimensão sensível, sensorial, afetiva e perceptual da experiência humana, sempre situada em continuidade com o ambiente. Esta relação recursiva de engajamento ambiental pode ser compreendida através da afecção, isto é, um coabitar no mundo que consiste em permanentemente afetar e ser afetado. Os ambientes onde estamos e por onde nos movemos ao longo de nossa vida - lugares ao mesmo tempo materiais e existenciais - nos constituem e, ao mesmo tempo, podem ser entendidos como generativos de uma ética do viver que se faz ao longo da nossa vida. O modo como nos tornamos habilidosos para lidar com esta jornada de modo mais ou menos ajustado aos nossos companheiros de existência implica em uma capacidade contínua de aprender e nos relacionarmos com tudo o que nos envolve. Para ampliar a compreensão da educação como intrínseca aos modos que criamos para viver e a via pela qual, todos os dias, nos tornamos o que somos, passaremos a algumas breves considerações sobre cada um dos nossos conceitos-chave.

\section{Estética}

Em primeiro lugar é necessário indicar que a noção de estética aqui acionada é demarcada desde o campo filosófico e se distingue da correlação simples e direta com o valor da beleza, do belo, da pessoa bela, ou ainda, da arte bela. Na educação ambiental o uso valorativo da noção de estética como sinônimo de beleza é bastante frequente. Afinal, a beleza das paisagens e o apelo à natureza como reserva do bom e do belo é bastante vigente em nossa história cultural moderna, pelo menos desde o ponto de inflexão no século VXIII que Thomas (1988) nomeia "as novas sensibilidades". Nenhum problema em aderir ao que aprendemos a ver como belo nas paisagens naturais. Contudo, é preciso ir adiante e enfrentar outros desdobramentos do que se abre a nós como uma experiência ético-estética, se quisermos ir além de uma educação ambiental que se reduz ao maravilhamento diante da natureza. O problema aqui é o lugar de externalidade reservado a esta visão da natureza como um espetáculo, um cenário paradisíaco que contemplamos de fora e de longe por alguns minutos antes de voltar às imperfeições da nossa "vida real".

Estética, no sentido que empregamos, está relacionada à palavra grega "aiesthesis", ou seja, a experiência sensível e a formação das sensibilidades que movem nossa ação no mundo. Neste sentido, coincidimos com a definição de estética operada por Herman (2008, p.18) em seu argumento sobre uma educação ético-estética como a arte do viver:

O termo estética, proveniente do grego aisthesis, significa sensação, sensibilidade, percepção pelos sentidos ou conhecimento sensível-sensorial. Esse termo aparece vinculado à ética já em Aristóteles, como um elemento decisivo para conduzir a vida, trazendo o papel do sensível para o julgamento moral, que nos ajuda a avaliar e a ponderar cada situação. Assim, desde a tradição grega, a aisthesis serve para articular as normas morais com a especificidade de cada situação concreta e refinar nossa capacidade de decidir.

\section{Afetos e Afecções}

Deste modo, se a noção de estética tal como demarcamos, está relacionada à formação de sensibilidades e ao conhecimento sensorial, ela nos leva necessariamente para o território dos afetos e das afecções. Tomaremos de Espinoza e de sua física dos corpos a contribuição fundamental para compreender estes dois modos de agir no mundo e ser "acionado" por ele. 
Originalmente estas noções aparecem nos livros I e III do Tratado da Ética, de Spinoza (2010 [1677]). Esta obra, escrita em latim, apresenta a noção de "affectio", que poderia ser traduzida por "afecção" e também a "affectus", que poderia ser traduzida por "afeto".

Para apresentar sinteticamente estas noções, no exíguo espaço deste tópico, contaremos com a ajuda de Guiles Deleuze (1978), em seu conhecido curso sobre Espinoza, em Vincenes. Neste curso, ele apresenta a obra do filósofo, de onde podemos destacar as seguintes proposições: o afeto (affectus) em Espinoza é a variação contínua da força de existir de alguém, na medida em que essa variação é determinada pelas ideias que esta pessoa tem. E aqui é preciso destacar que em Espinoza ideia não é uma representação imaterial e descolada das coisas, mas efeito das coisas, portanto, algo muito mais material do que numa perspectiva idealista. Também a afirmação de variação da força de existir sendo "determinada" não quer dizer que a variação se reduza às ideias que uma pessoa possui, uma vez que a ideia que eu tenho só dá conta de sua consequência, a saber, que ela aumente minha potência de agir ou, ao contrário, a diminua em relação à ideia que eu tinha imediatamente antes, e não se trata de uma comparação, trata-se de uma espécie de deslizamento, de queda ou de elevação da potência de agir.

A afecção é o estado de um corpo que sofre a ação de um outro corpo, ou em outras palavras, é afetado por outro corpo, humano ou não humano. Assim, o outro corpo ao qual Spinoza se refere pode ser uma pessoa, um acontecimento, um evento natural, elementos da natureza, ampliando o sentido de alteridade. A pergunta que indicaria a afecção seria: como algo me afeta? Deleuze exemplifica: "Eu sinto o sol sobre mim", ou então, "um raio de sol pousa sobre você": esta é uma afecção do seu corpo. E o que afeta seu corpo? Não o sol, mas a ação do sol ou o efeito do sol sobre você. Em outros termos, um efeito, ou a ação que um corpo produz sobre outro - note-se que Spinoza, por razões decorrentes de sua física, não acredita em uma ação à distância: a ação implica sempre um contato - é uma mistura de corpos. A afecção (affectio), portanto, é esta combinação muito concreta entre dois corpos, um corpo que se diz agir sobre outro e um corpo que recolhe o traço do primeiro. Toda mistura de corpos será chamada por Espinoza de afecção.

\section{Percepção}

Juntamente com a sensibilidade estética, afeto e afecção, a percepção também constitui parte de nosso aparato vital para nos situarmos no mundo. O modo como somos afetados pelo mundo e como respondemos a isso passa fundamentalmente por nossa capacidade de perceber o ambiente, tanto em termos de uma auto percepção como do que da percepção do ambiente que nos envolve. É na abordagem fenomenológica, particularmente na contribuição de Merleau-Ponty, que encontramos o conceito de percepção que nos parece mais produtivo para compreender as relações de profundo engajamento com o ambiente. Desde A Fenomenologia da Percepção, Merleau-Ponty (1971) preocupa-se em postular a percepção como operação fundamental do modo de habitar o mundo, mediado pela corporeidade. Afastando-se de uma visão cognitivista dos processos perceptivos Merleau-Ponty trata dos processos perceptivos levando em conta as dimensões físicas do ambiente e biológicas dos corpos sem, no entanto, aceitar as explicações reducionistas da percepção como um processo exclusivamente orgânico ou mental. Essas dimensões não são negadas, mas situadas dentro de um círculo virtuoso, no qual sujeito e objeto se constituem mutuamente numa prática ao mesmo tempo criativa e estruturada. Ou seja, o sujeito, ao mesmo tempo em que age em direção ao mundo e aos objetos, também é constituído pelo mundo e pelos objetos em direção aos quais ele se move. Para Merleau-Ponty, o mundo sustenta o corpo do sujeito e se move com ele, demarcando o seu campo da exploração perceptual e experiencial. Como condição corporal do sujeito, o mundo é experienciado como constitutivo do sujeito-corpo que o habita e não mais apenas como um referente externo e objetivo aos sujeitos que nele se movem. 
Abram (1996), num instigante artigo sobre Merleau-Ponty e a questão ambiental, argumenta em favor da contribuição da fenomenologia, particularmente no último trabalho de Merleau-Ponty, O visível e o invisível (1968), como fundamento para uma filosofia da natureza que aponta para a possibilidade de superação dos impasses da ecologia herdeira da tradição biológica mecanicista na compreensão da relação sujeito humano e ambiente:

Nossa civilizada desconfiança dos sentidos e do corpo engendra um descolamento metafísico do mundo sensível - isso alimenta a ilusão de que nós mesmos não fazemos parte do mundo que estudamos, do qual podemos nos manter à parte, como espectadores, e assim determinar seu funcionamento desde fora. Uma renovada atenção para a experiência corporal, no entanto, permite-nos reconhecer e afirmar nosso envolvimento inevitável naquilo que observamos, nossa imersão corporal nas profundezas de um corpo que respira e que é muito maior do que o nosso próprio corpo (ABRAM, 1996, p.85).

Esta comunhão entre o corpo humano e o corpo do mundo, que engloba e transcende o do indivíduo, é denominada em $O$ visível e o invisível, com o termo "carne" e se apresenta como o elo comum entre o humano sensiente e o mundo sensível. Ou seja, na expressão de MerleauPonty,

Há um corpo da mente e uma mente do corpo... A noção essencial desta filosofia é a carne, que não é o corpo objetivo nem o corpo pensado pela alma (Descartes), [mas] o qual é o sensível no sentido daquele que é sentido e do que sente (1968, p.259).

Com essa noção de "carne”, Merleau-Ponty radicaliza o que já apontava com a noção de corpo, no sentido agora de uma transcendência do sujeito no mundo do qual o corpo humano é uma expressão. Ao invés da posição cartesiana de um sujeito que pensa e, portanto, existe, ou ainda, que pensa o mundo com uma mente à parte do mundo, na perspectiva fenomenológica, o mundo pensa no sujeito que existe na relação de continuidade e distinção como uma das expressões da carne do mundo, cuja diferença está na forma de exercer a reflexividade. Como afirma Merleau-Ponty, "a carne do mundo não sente a si mesma como minha carne. Ela é sensível, mas não sensiente. Eu chamo isto de carne, no entanto, para dizer que isto não é absolutamente apenas um objeto" (1968, p.250).

É importante observar que o conceito de carne em Merleau-Ponty contribui significativamente para a superação da posição antropocêntrica que transforma todo não humano em mero objeto. Diferentemente da crítica da ecologia profunda que, ao se posicionar a favor do biocentrismo contra o antropocentrismo, apenas muda de pólo, sem alterar a relação de submissão entre humanos e não-humanos, Merleau-Ponty chama a atenção para o entrelaçamento denso e extensivo entre estes pólos como uma mesma carne, ao mesmo tempo em que reconhece que o processo de autoconsciência em cada um deles não é idêntico. Assim, a carne que pensa no ser humano não pensa do mesmo modo nos outros seres sensientes. Sua posição evita tanto a fusão ou dissolução da singularidade humana no bios do mundo quanto a arrogância humana que se posiciona fora do mundo. Pode-se concluir, portanto, que o conceito de carne de Merleau-Ponty estabelece uma continuidade entre o corpo humano e a carne do mundo.

\section{Somos a Carne do Mundo}

Ao realizarmos uma caminhada em meio a um ecossistema natural, como o fizemos durante o experimento educativo do qual tratamos neste artigo, podemos nos referir sobre nossa percepção do ambiente trilhado. Também poderíamos aqui usar a palavra paisagem para o que avistamos, mas seria preciso ajustar esta expressão, se quisermos ser coerentes com a base epistemológica aqui proposta. A paisagem, em nosso caso, seria uma unidade coerente do "visível", isto é, o campo de engajamento perceptivo de aqueles que a habitam (ainda que apenas durante algumas horas de uma trilha, ou alguns dias de um acampamento). Neste 
sentido, o que vivemos não se restringe a uma visão contemplativa de algo externo a nós, mas a experiência de constituir um campo de forças onde diversas formas de vida, incluindo nossa presença humana, afetam umas as outras e são reciprocamente afetadas. Uma totalidade dinâmica dentro da qual todos os seres sensíveis estão inseridos. Como afirma Abram, numa referência direta ao pensamento de Merleau-Ponty, "a paisagem não é a totalidade abstrata de um universo inteligível, mas a unidade experienciada deste continente que nos abriga na forma de um mundo local a que chamamos Terra" (1996, p.86). Neste sentido, poderíamos ver alguma convergência entre a física dos corpos em Espinoza e a afirmação de Merleau-Ponty de que somos a carne do mundo, em continuidade com o tecido vivo que constitui o fluxo de vida ao qual pertencemos. Seja pelos bons ou maus encontros, seja pela potência de sermos alegres ou pela potência de padecer, estamos sempre engajados numa troca contínua com a vida que somos e que nos engloba. Uma educação ético-estética, ao tornar presente estas dimensões de nossa experiência no mundo, poderia contribuir para, ao menos, diminuir a ilusão de autonomia do humano em relação ao ambiente e as outras formas de vida que onipotência da Razão há tantos séculos insiste em afirmar.

\section{Conceptualization - Practice/Actions of being a researcher - Laísa \& Claudio's narrative ${ }^{8}$}

Cómo, y de qué manera, fue la 'experiencia' del medioambiente/'naturaleza' (en un Bosque Atlántico modificado) construida (pedagógicamente a través de las interacciones/comunicaciones/relaciones de los participantes) como 'otorgada' mientras moviéndose/caminando por el sendero del bosque? La pregunta específica: dónde estaba (sensorialmente) la afectividad presenciada (y no presenciada)?

Luego del primer día de workshop (subtema 04 - aesthetics $\sim$ ethics politics) donde revisamos (a modo de introducción) la conceptualización de las nociones de 'afectividad' y 'estética', podemos decir que la experiencia del workshop ha cambiado el 'lugar' (o el rol) de las experiencias estéticas en la investigación en educación ambiental, en nuestra percepción como investigadores emergentes. De acuerdo a la literatura conocida anteriormente por nosotros, nuestros planteamientos eran que las experiencias estéticas contribuyen a la adquisición de contenidos. Por ejemplo, Seniciato y Cavassan (2004) sugieren que las emociones y sensaciones durante una actividad en terreno en un ambiente natural, pueden colaborar con el aprendizaje de contenidos ecológicos dado que los estudiantes movilizan valores, además de la razón para la comprensión de fenómenos. En 2009, los mismos autores añaden a la información de que durante actividades en terreno, interacciones entre profesor, estudiante y ambiente (entorno) generan buenos recuerdos a través de las experiencias estéticas proporcionadas por las actividades (SENICIATO; CAVASSAN, 2009).

Sin embargo, en el workshop las experiencias estéticas fueron caracterizadas como importantes por ellas mismas, y no solamente vistas como algo secundario para crear ambientes de aprendizaje de contenidos conceptuales, cosa que fue novedosa y a la vez desafiante para nosotros ambos (Laísa y Claudio). Profundizando en esta discusión, de cómo respondimos a nuevas miradas teóricas y prácticas en la investigación en educación ambiental, al trabajar la relación estética ética política, consideramos que en investigaciones actuales impartidas, por ejemplo, en Brasil (p.ej. BRASIL, 2004), y en particular en el caso del grupo de investigación de Laísa (p.ej. JULIANI; FREIRE, 2014), el énfasis de las investigaciones llevadas a cabo están más relacionados y enfocados en los aspectos políticos de la educación ambiental, tal vez

\footnotetext{
${ }^{8}$ En esta sección Laísa e Claudio escriben en primera y tercera persona debido a su doble rol como 'investigadoresinvestigados'.
} 
debido a la tradición de emancipación social propia de la escuela Brasilera de educación ambiental.

Desde los estudios críticos del discurso, los cuáles utiliza Laísa en cuanto a referente teórico para trabajar la educación ambiental, hay un compromiso con el cambio social que trae el enfrentamiento de problemas y cuestiones socioambientales. Además, desde el marco teórico y metodológico del análisis crítico del discurso, las dimensiones de los valores, de las creencias, de las actividades mentales y de las actividades materiales son otras las dimensiones presentes en las prácticas sociales además de la discursiva (CHOULIARAKI; FAIRCLOUGH, 1999). Esta mirada nos lleva al cuestionamiento de cómo acceder a la dimensión afectiva sin analizar el lenguaje? O mejor dicho, qué aspectos del lenguaje informan los aspectos estéticos y cómo eso genera metodologías de investigación?

Para Claudio, el tema del rol e importancia de las 'emociones' y 'afectividades' en educación ambiental le era familiar desde sus intereses de investigación en el uso de las Tecnologías de la Información y Comunicación (TICs) para la educación socio-ecológica de comunidades. En esta área de la literatura se subraya la importancia de aflorar emociones y afectividades para el aprendizaje socio-ecológico no-formal (BALLANTYNE; PACKER, 2005; EICH; SCHOOLER, 2000). En este sentido, es posible aflorar emociones y afecciones en el aprendizaje socio-ecológico a través del uso de herramientas TICs, por ejemplo, con videos online (AGUAYO, 2014). Un punto importante que indica Aguayo (2014) es que los usuarios deben 'sentir' una proximidad con el caso de estudio en cuestión (p.ej. el deterioro ecológico de su ecosistema local), basado en vivencias eco-afectivas anteriores.

Dentro de este contexto tecno-afectivo, el caso de Claudio es un poco distinto al abordaje de los estudios del lenguaje donde se sitúa Laísa. En el último tiempo Claudio ha estado dedicado a investigar el cómo acoplar el uso de tecnologías móviles para el aprendizaje, con especial énfasis en la adaptación a los contextos y particularidades de la cultura local en dónde éstas tecnologías educacionales son implementadas. Decimos que es distinto porque las dimensiones emocional, afectiva y, por ejemplo, espiritual pueden estar muy presentes en dichas culturas. Sin embargo, Claudio como investigador muchas veces ajeno a dichas culturas locales, a veces se ha visto enfrentado a la problemática de cómo aflorar dimensiones afectivas y emocionales desde el punto de vista de un investigador ajeno a una cultura determinada? Cómo lograr penetrar una cultura poco conocida, y una dimensión afectivo-emocional propia de una cultura ajena, a través de la tecnología? En este sentido, en el grupo de investigación de Claudio se habla mucho de la importancia de las instancias 'offline' (the face-to-face dimension) en el uso de las tecnologías para la educación, que son instancias donde podrían caer los conceptos de afectividad y estética, lo que para Claudio hace sentido, sin dejar de lado la potencialidad de las instancias 'online', o basadas en el uso de la tecnología, para lograr dicho propósito..

A partir de tantos cuestionamientos e interrogantes que nos surgieron luego del primer día de workshop, la propuesta para el segundo día fue contextualizar la conceptualización del día anterior. Esto implicó vivir una experiencia nueva y práctica (aplicada) como investigadores novatos en lo afectivo-estético, y ser participantes a la vez, basada en una teoría y metodología prácticamente nueva y poco conocida. Dicha experiencia fue muy atractiva, desafiante e importante de experimentar. Esto además nos ayudó a conceptualizar otras miradas posibles en la investigación en educación ambiental. Miradas que hoy vemos en retrospectiva como importantes y atingentes, particularmente en nuestro camino como investigadores emergentes en educación ambiental. Fue así que para contextualizar y vivir la experiencia, buscamos traer elementos de la 'etnografía caminada' (walking ethnography) que revisamos durante el primer día de workshop, como por ejemplo, realizar toma de datos durante la walking ethnography y tener la experiencia de analizar los aspectos estéticos, afectivos y emocionales que podrían ser proporcionados durante el recorrido de la caminata al aire libre. Nótese que en esta actividad al 
aire libre nos hemos enfocado particularmente en modos de hacer investigación en torno al tema estético, sin considerar explícitamente los subtemas relacionados a aspectos políticos y/o éticos.

Estar en contacto con la naturaleza e interactuar con ella fue una experiencia muy agradable para nosotros, tal vez especialmente para Claudio ya que se trataba de un ecosistema totalmente desconocido y novedoso para él (la Mata Atlântica). Ésta experiencia fue agradable y placentera desde el momento de escoger la ropa que consideramos adecuada para una actividad en sendero al aire libre, a todo el hecho de caminar y compartir con colegas y amigos nuevos, cruzar un río en barco, mirar el sendero desde un punto de vista nuevo con sus múltiples funciones, u objetivos pedagógicos, que van más allá de adquirir contenidos ecológicos, botánicos, geográficos y de conocimiento cultural local (on-line picture album Day 2 Contextualization). Además de lo anterior, fue una experiencia muy especial porque ambos teníamos la 'misión' de ser investigadores, y participantes al mismo tiempo, basándonos en una teoría nueva, desconocida, pero atractiva, que queríamos descubrir y vivenciar, y que al fin y al cabo nos hacía mucho sentido explorar, tanto como individuos, como investigadores emergentes en educación ambiental.

El sendero y nuestra actividad investigadora empezaron en Bertioga-SP, donde nos subimos al autobús que nos llevaría hasta el punto inicial de la caminata. Las experiencias estéticas fueron vividas y reflexionadas desde ese mismísimo momento. Para eso, fuimos tomando apuntes y notas personales (según lo acordado con nuestro grupo de workshop), y platicamos entre nosotros, lo que fue muy agradable, puesto que juntos construimos una mirada estética durante el sendero. Además, como estábamos siempre pendientes de nuestro rol de investigadores, a cada rato íbamos platicando con Phil (coordinador del workshop) quién nos fue 'guiando' in situ a lo largo de nuestra investigación exploratoria durante la caminata, ejerciendo su rol de mentor de la actividad. Por ello, a veces nos solicitaba observar determinadas cosas (por ejemplo, señales del ser humano en el sendero - como una lata de refresco tirada al suelo) y reacciones del grupo (por ejemple, al cruzar la lata). También trataba de indicar que a veces estuviéramos juntos en puntos específicos del sendero y en otros momentos que estuviéramos separados.

Entre las diferentes experiencias vivencialmente nuevas que nos transformaron por cómo las aproximamos y que nos afectaron durante el sendero se pueden destacar las siguientes: experimentar el gusano del coco de la Palmeira-indaiá (particularmente delicioso para un gusano!) (on-line picture album Day 2 - Contextualization - Atlantic Forest - photo Atlantic Forest 6); sentir diferentes olores (de hojas, de animales, de tierra); entrar y bañarnos en una cascada; observar vegetación y fauna; observar y utilizar construcciones humanas que contrastaban con la naturaleza presente como cruzar un puente peatonal antiguo, observar y caminar sobre las vías de un ferrocarril en la mitad de la selva, torres de energía que parecían fuera de lugar (on-line picture album Day 2 - Contextualization - Mangrove Swamp - photo Mangrove Swamp 8; Atlantic Forest - photo Atlantic Forest 5); la raíz tabular del árbol (Samaúma) y su uso cultural por los nativos del lugar. En estas experiencias pudimos ir más allá de la información ecológica y botánica típica/clásica/científica que uno de los guías resaltaba, a un tipo de experiencia estética de tocar, saborear y sentir, por ejemplo, la textura del tronco, el sonido al "pegar" la raíz de Samaúma con un palo (on-line picture album Day 2 Contextualization - Atlantic Forest - photo Atlantic Forest 7); y juntar dicha experiencia con la información del uso ancestral y cultural local del uso de la raíz para la comunicación de grupos indígenas que han vivido en la región por generaciones, lo que nos fue explicado por otro guía .

A través de la experiencia generamos una combinación entre nuestros cuerpos y la naturaleza ('cuerpo' de acuerdo a lo planteado en la conceptualización), y en estos encuentros cambiamos como personas. Además, cada vez que nos acordamos del sendero y de la 
experiencia, podemos de algún modo revivir y reinterpretar la experiencia y cómo fuimos afectados por el medio ambiente.

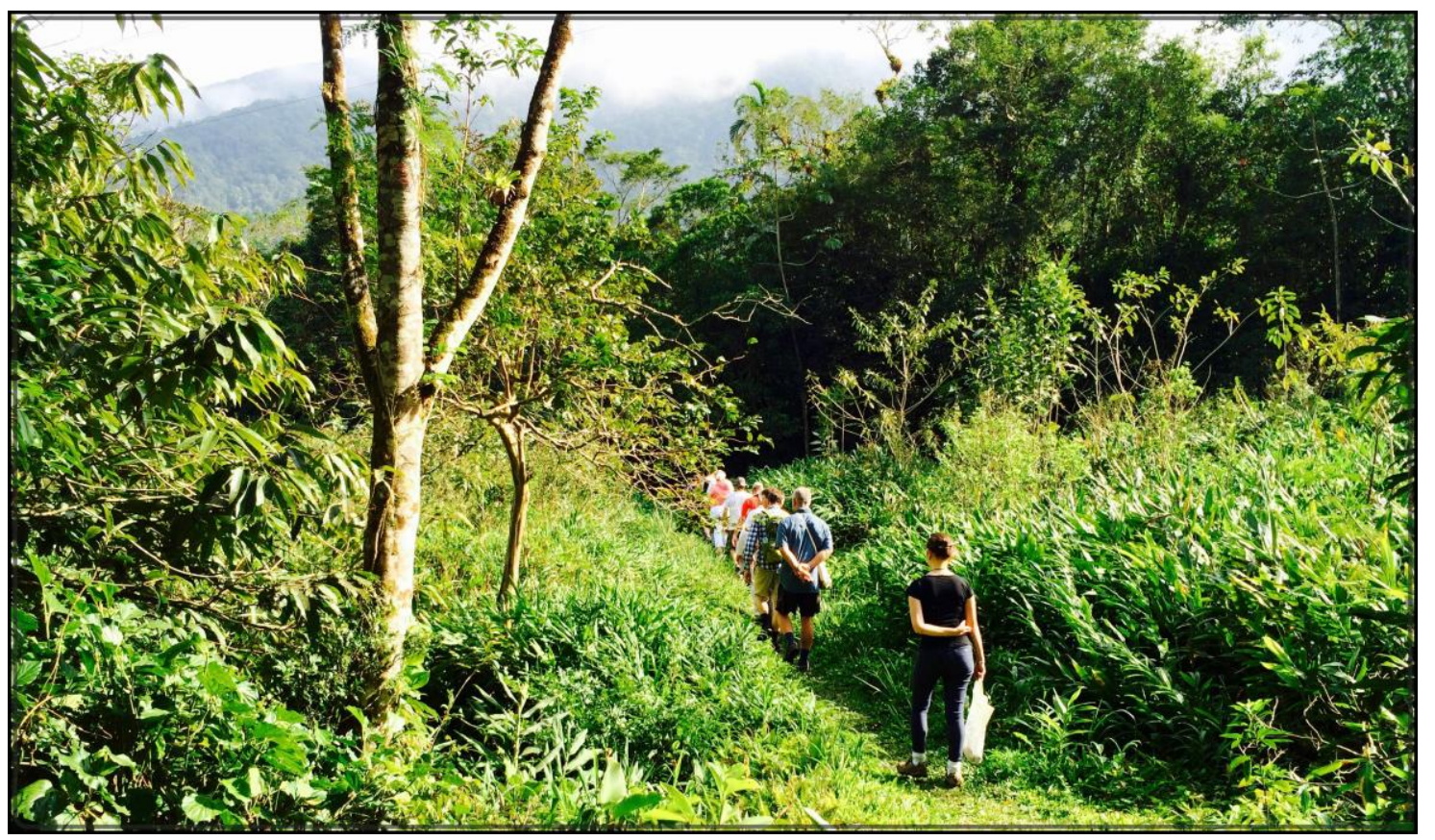

(Moviéndose, caminando, sintiendo)

Respecto a nuestra experiencia de 'walk the talk', o de contextualizar en terreno la conceptualización teórica del día anterior, podemos decir que para Laísa lo que más le quedó dando vueltas fue el cómo las metodologías tradicionales/clásicas de investigación en educación ambiental chocaban, o desafiaban, el rol de investigar/observar y reportear lo ecoestético y vivencial de lo que es la walking ethnography. En particular, los desafíos personales para ella fueron tratar de acoplar metodologías de un tipo, con experiencias de otro tipo que, según ahora entendemos, no necesariamente tienen un punto de encuentro lógico, si es que lo 'lógico' tiene sentido en lo estético pre-discursivo, o pre-lingüístico. En resumen, el desafío fue comprender la vivencia como investigación y superar el 'choque' entre metodologías tradicionales con metodologías más apropiadas para la investigación eco-estética y ecosomática. Sin embargo, Laísa pronto trabajará el aspecto estético como experiencia práctica, pues ha tenido un proyecto recién aprobado en educación ambiental en donde pretende explorar los aspectos estéticos y afectivos en el contexto de hacer una ruta para un sendero en Amazonia.

En cuanto que para Claudio, más que un desafío lo que ocurrió con él fue una reflexión sobre la importancia de incluir, de alguna u otra manera (y ahí radica su 'desafío' personal), experiencias estéticas, eco-somáticas y vivenciales como parte de lo que es 'usar' la tecnología para la educación ambiental. Un poco relacionado al tema de la importancia de las instancias offline y face-to-face en el uso de las tecnologías para promover comunidades socioecológicamente sustentables, y cómo emplear lo afectivo en dicho proceso. Esto se refiere a la importancia de siempre incluir, e incluso partir desde, lo visceral al momento de tratar temas ligados al medio ambiente usando la tecnología, ya que, si bien hoy en día la tecnología puede ser de gran ayuda para la educación ambiental, si no incluímos un componente carnal-somático(pre)cognitivo, podemos estar siendo infieles a nuestra naturaleza humana, y caer en el juego de la 'colonización digital'.

Lo que sí concordamos ambos luego del workshop aesthetics ethics politics, y de nuestra experiencia durante la caminata al aire libre, es que es más que necesario explorar e impregnarse como investigadores emergentes en educación ambiental con otras formas y 
perspectivas, muchas veces no tradicionales e incluso a veces culturalmente tabúes (por ejemplo el uso de psicotrópicos para explorar e investigar dimensiones estéticas), de ver/entender/sentir/vivenciar/comprender el mundo natural que nos rodea y del cuál conformamos parte íntegra, con el mundo cognitivo interno/estético-somático/psicológico que nos permite llegar al punto de encuentro con dicho mundo natural, y el enorme potencial que esto tiene para (re-transformar?) la educación ambiental en estos tiempos de gran incertidumbre global. Más aún, creemos que es vital integrar estos aspectos con temas más políticos y sociales propios del contexto Latinoamericano de la educación ambiental.

En esta sección intentamos presentar nuestras reflexiones sobre el workshop aesthetics $\sim$ ethics politics. En este punto quisiéramos ser claros en establecer que esta narrativa proviene de nuestras propias vivencias y percepciones personales de lo que fue la experiencia y participación en este workshop, y que pueden diferir de las percepciones de los otros participantes del workshop. En ese sentido, entendemos que muchas veces las narrativas pueden ser estereotipos que se hacen respecto a una percepción de una historia y/o realidad parcial o subjetiva.

Volviendo al concepto de que somos la carne del mundo introducido al principio de este artículo, a la vez que vemos en retrospectiva nuestra experiencia teórico-práctica durante el workshop, ambos también logramos entender la visión de cómo nuestro 'compromiso' ambiental (tanto como educadores, investigadores e 'investigados') puede ser entendido como un continuo entre la afección, la estética y los sentimientos en una totalidad dinámica dentro de la cuál todos los seres sensibles estamos insertos, a través de nuestra corporalidad, nuestra percepción, y la carne de nuestro medioambiente que nos engloba, nos nutre, y nos mantiene vivos y con vida.

\section{O olhar das/os pesquisadoras/es emergentes}

Recentemente, defendi minha tese de doutorado (IARED, 2015) que tinha como questão central compreender quais as experiências estéticas no Cerrado de um grupo de 17 participantes com um histórico de envolvimento afetivo com o bioma. Para tanto, adotei uma abordagem fenomenológica-hermenêutica e iniciei a coleta dos meus dados realizando entrevistas individuais e semi-estruturadas sobre as memórias e vivências de cada um no Cerrado. A fenomenologia busca compreender a experiência que ocorre em um nível pré-reflexivo, anterior a linguagem (MERLEAU-PONTY, 1971). Ora, se meu objetivo é trazer à luz esse nível anterior a linguagem, não parece insuficiente acessá-lo e representá-lo "apenas" pelas entrevistas? Ao realizar um aprofundamento da literatura contemporânea me depararei com a "etnografia em movimento" ou "etnografia sensorial" (walking ethnography/ mobile studies/ sensory ethnography $)^{9}$ (INGOLD; VERGUNST, 2008; LORIMER, 2011; PINK, 2009), o que me fez voltar a campo e complementar meus dados usando essa metodologia. Na revisão de literatura sobre o assunto, encontrei artigos que utilizaram diferentes técnicas para coletar seus dados, mas percebi duas preocupações recorrentes: a) atenção com a representação da vivência, por ser uma prática que foca o sensorial e não o verbal/textual, o que culmina na segunda preocupação; b) corpo engajado da/o pesquisador/a por trazer a perspectiva de que também vivenciemos a experiência e, mais do que estarmos nos descrevendo ou relatando um fenômeno, estamos todas/os com nossos corpos imersos na vivência. A partir da caminhada no Cerrado, optei pela elaboração de narrativas, pois, segundo Payne (2013), são formas de representação que recapturam a experiência corpo-espaço-tempo na natureza e, consequentemente, são sugestivos para a compreensão das respostas afetivas do corpo-mente no mundo.

\footnotetext{
${ }^{9}$ Tradução livre. Temos optado por manter o termo em inglês: walking ethnography ou mobile studies ou sensory ethnography.
} 
Meu desafio aqui, novamente, é elaborar uma narrativa sobre a experiência de dois pesquisadoras/es emergentes, Laísa e Claudio, que participaram do grupo do Subtema 04 (Aesthetics, Ethics and Politics) durante o $13^{\text {th }}$ Invitational Seminar on Research Development in Environmental Education. No primeiro dia de atividades, houve uma contextualização e conceitualização da teoria entre as/os participantes do grupo. Na manhã seguinte, realizamos um exercício do walking ethnography em uma saída de campo em uma trilha na Mata Atlântica de Bertioga, SP. Sendo assim, descrevo nossa vivência (Laísa e Claudio) de imersão nessa teoria ao mesmo tempo em que no ambiente natural como uma tentativa de representar nossa experiência estética da natureza e do aprender.

\section{Segunda Narrativa}

Iniciamos o trabalho do primeiro dia levantando uma chuva de ideias sobre a temática do Subtema 04. Laísa e Claudio, apesar de já próximos do campo da educação ambiental, perceberam esse referencial teórico-metodológico como novo. Muitas dúvidas e questões interessantes surgiram a partir dessa busca por entender, principalmente, a representação das experiências vividas. Ao pararmos para o almoço, o grupo se dividiu e Claudio aproveitou esse tempo livre de cada um para mergulhar na piscina. Quando voltamos para a sala onde estávamos trabalhando, Claudio foi instigado a falar como foi sua experiência de sair para um banho no intervalo. Claudio começou justificando o que o impulsionou a um mergulho e não achava as palavras certas para relatar como tinham sido prazerosos aqueles poucos minutos de relaxamento. Ele, então, abriu um sorriso e disse ter entendido o problema que estávamos abordando pela manhã. Continuamos o trabalho pela tarde adentro um pouco incomodados com o calor e o fato de termos um ambiente externo convidativo, mas não explorado em sua totalidade. No final do primeiro dia, concordamos em praticarmos no dia seguinte, na trilha, a metodologia que estávamos apenas falando e lendo sobre.

Amanheceu uma linda manhã de sol e fomos todas/os a caminho da trilha. A trilha começa em uma margem de um rio, então pegamos um barco para atravessar um pequeno

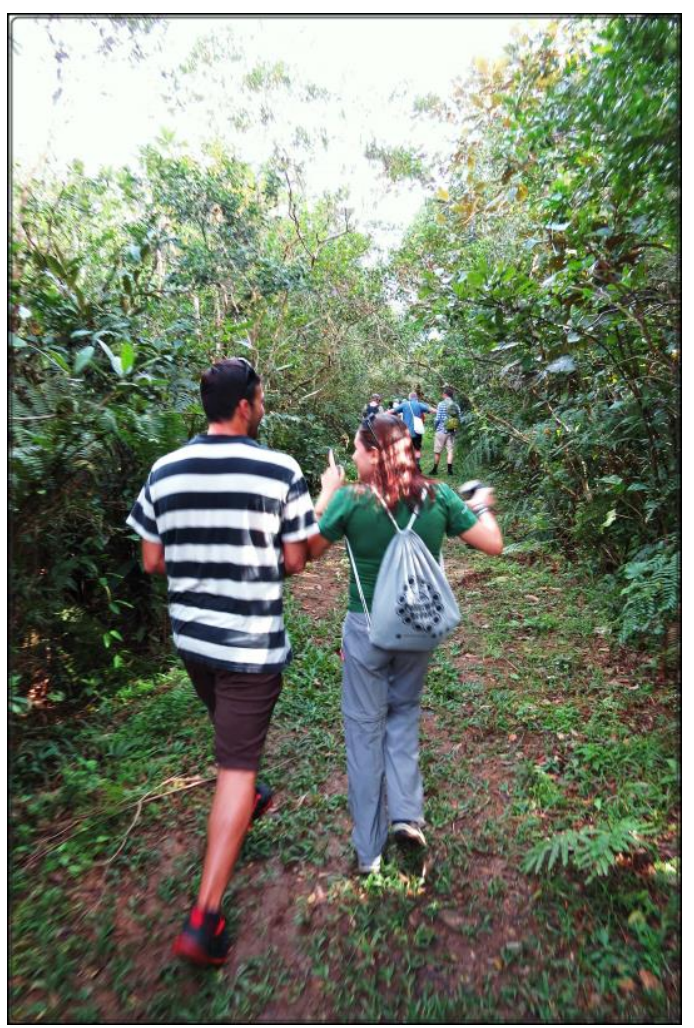
trecho de água. Laísa parecia curiosa e ansiosa em passar por esse exercício do walking ethnography, enquanto Claudio, mais calmo, apenas sorria, iniciando sua caminhada tranquilamente. Laísa e Claudio começaram a trilha andando separados $e$ por vários minutos se viram imersos em um trecho de mangue. Andavam atentos aos detalhes daquele ambiente, algumas vezes relatando o que estavam vendo, ouvindo e sentindo. Apesar de imersos nesse ambiente contemplativo, Laísa se deu conta que tinha também outro papel naquele momento: o de ser pesquisadora. Então, aproximou-se de Claudio para uma conversa descontraída. Quando separados, eles se posicionavam entre lados opostos do grupo, mas a natureza também solicitava atenção e, em muitos trechos, estavam simplesmente imersos na natureza, assim como o restante do grupo. De repente, "lembravam" que, além de participantes, eram pesquisadoras/es, o que fez com que Laísa corresse muitas vezes entre o grupo procurando estar em um lugar diferente de Claudio. Esse movimento de se aproximarem e afastarem 
aconteceu durante todo o percurso da trilha e sempre entre sorrisos e olhares curiosos, ambos foram vivenciando esse espaço como participante e (Claudio e Laísa na Trilha d'água) como pesquisador/a.

No percurso de volta da trilha, havia uma cachoeira refrescante e convidativa. Laísa e Claudio se despiram da função de pesquisador/a e de suas roupas para mergulhar na água fria da cachoeira. Roupas e caderno de anotações ficaram entre as pedras para dar lugar a um banho divertido, agradável e revigorante! Após o banho na cachoeira, Laísa e Claudio voltaram mais relaxados, silenciosos e menos presos às suas observações e anotações.

Reunimo-nos novamente à noite para conversarmos sobre essa atividade. Laísa e Claudio sorriam satisfeitos com o que haviam realizado. Liam suas anotações ao mesmo tempo em que descreviam o ambiente, a história. Como todas/os tínhamos vivenciado a atividade, sabíamos do que eles estavam falando. Para Laísa e Claudio, tudo parecia fazer sentido!

A perspectiva de redigir uma narrativa nesse contexto de participantes e pesquisadoras/es estarem imersos na mesma experiência traz à tona um ponto essencial na pesquisa interpretativa que é o fato de questionar o conceito de objeto de estudo e observador/a. Ou seja, a/o pesquisador/a "faz parte" da pesquisa, ao contrário da perspectiva de que a/o pesquisador/a "interfere" na pesquisa. Nesse sentido, a narrativa, em vários momentos, traz a visão do "nós" e não, somente, de Laísa e Claudio. Ao invés deles estarem descrevendo a experiência em forma de entrevista para a/o pesquisador/a, todas/os nós estávamos lá engajados, cada qual com seu corpo e sua percepção de mundo, mas na mesma atividade prática. Isso não é negar a entrevista e outras técnicas de coleta de dados, que, inclusive, podem complementar e estender a discussão dos dados na investigação (IARED, 2015; KUSENBACH, 2003). Essa prática foi apenas um exercício, sendo que a aplicação dessa metodologia solicita um estudo mais profundo da teoria e a revisão de literatura na área por parte das/os pesquisadoras/es que fazem essa opção.

\section{Unindo olhares...ligando pontos...}

“O que é crítico em pesquisas 'críticas' contemporâneas em educação ambiental: desafios teóricos, tensões, aplicações, implicações metodológicas?”. Foi essa questão que reuniu os autores deste trabalho em julho de 2015 , na cidade de Bertioga, durante o " $13^{\circ}$ seminário (invitational) sobre desenvolvimento de pesquisa em educação ambiental", no qual o "trabalho generativo" tem sido marca desde o primeiro encontro, em 1994, na Dinamarca. Pensando nessa questão desafiadora durante o sub-tema estética-ética-política, desafios teóricos, tensões, aplicações e implicações metodológicas do "crítico" em educação ambiental crítica contrastaram com a lacuna teórico-prática associada ao papel da estética e da afetividade na (pesquisa em) educação ambiental. Esta indagação inicial levou a uma série de outras perguntas desafiadoras: como poderiam estética/afeto/sentimento/emoção ser representadas e enquadradas na educação ambiental crítica? Como podemos medir e avaliar paixão, raiva, desejo? Como se coletam dados em relação à estética e como valorizar e validar esses dados? Como isto se traduz em metodologias, perguntas de pesquisa, conhecimentos científicos "objetivos"? A afetividade da estética pode ser pensada apenas no "processo" préconsciente/corporal de construção de significados no movimentar-se ecologicamente, ou mesmo na aprendizagem "racional" (formas de aprendizagem) ou pode/deve apontar para um status de conhecimento, estado tipicamente atribuído à ética e política (epistemologicamente conduzidas)? Antes de pensar sobre questões que envolvem o "como", "por que" a estética é importante na educação ambiental (crítica)? 
Pensar sobre estas questões é consistente com as finalidades de pesquisa em educação ambiental crítica. Ao pensar sobre os pressupostos ontológicos, interesses epistemológicos e deliberações metodológicas da pesquisa em educação ambiental, o desafio principal permanece sendo a concretude de uma prática não idealista. Isto significa almejar e consolidar justas e transformadoras práticas pedagógicas, políticas, de currículo e de pesquisa. Isto sendo um objetivo legítimo e reconhecido da (pesquisa em) educação ambiental, de modo geral, vivemos de isoladas, e de pequena escala, histórias de sucesso. Barreiras históricas e lacunas ainda são fortes: barreiras linguísticas e geo-epistemológicas; lacunas teorico-práticas; oposições objetivo-quantitativo/subjetivo-qualitativo, materialista-ontológica; princípios/objetivos idealistas e limites para a mudança ignorados. Minar estas barreiras significa materialisticamente/realisticamente e simbolicamente/textualmente de/reconstruir a educação (ambiental) - isso implica na elaboração de questões de pesquisa "difíceis", baseadas em conceituações adequadas, sustentadas por experimentações com deliberações metodológicas apropriadas e criativas, conscientes de suas próprias limitações, resultando em interpretações e representações de conclusões perspicazes e robustas que, legitimadas pelo auto-reconhecimento de sua parcialidade, refletem, de forma práxica, os objetivos iniciais da tarefa de pesquisa.

O "auto-estudo" de pequena escala descrito neste manuscrito foi desafiador e generativo ao propor perguntas difíceis, ao pensar sobre um problema pré-concebido (o que é crítico na pesquisa contemporânea em educação ambiental "crítica"?), através de um prisma prédeterminado (estética-ética-política). Pesando sobre estas questões a experiência de cada pesquisador em (pesquisa em) educação ambiental, todos diferentes em idade e contextos geoculturais, bem como pré-leituras circuladas previamente entre os participantes do sub-tema, todo esse conjunto sendo crucial para um processo de conceituação adequado. A partir disso, foi formulada uma pergunta de pesquisa, sustentada por um "exercício" de contextualização ("caminhar" na floresta local), com deliberações metodológicas adequadas e criativas (walking ethnography), cientes de suas próprias limitações ("apenas" um exercício, aquém dos compromissos necessários para a realização plena de tal metodologia).

$\mathrm{Na}$ representação coerente das interpretações desta experiência, os pesquisadores, totalmente expostos como "observadores" e "observados", se unem novamente na co-autoria deste manuscrito participativo, interativo e iterativo. Consciencioso do compromisso necessário à teoria na pesquisa em educação ambiental apresenta uma robusta conceituação da noção de afetividade e estética; consciencioso do potencial desses elementos no enquadramento e na condução de pesquisas em educação ambiental, apresenta narrativas pessoais e significativas de "experiências do caminhar" de diferentes corpos que sentem e que falam; consciencioso da necessária (re)significação criativa na pesquisa em educação ambiental que desafiem lacunas e barreiras históricas no campo, apresenta um método de escrita respeitoso das afetividades, sensibilidades e subjetividades geo-cultural-ecológicas dos co-autores e coerente aos objetivos éticos, políticos e metodológicos da tarefa de pesquisa.

Desde a pré-concepção do sub-tema estética-ética-política do $13^{\circ}$ seminário, ao workshop de dois dias e seguintes experiências e diálogos durante e após o seminário, "desaguando" nesta representação escrita como síntese geral, o objetivo tem sido gerar significado sobre o conceito de ecosomaesthetics (ecosomaestética) necessário em uma nova linguagem de educação ambiental. Isso não significa um novo começo. Implica, no entanto, novos horizontes, principalmente sobre o lugar da estética (ambiental) e a importância da afetividade em como podemos conduzir pesquisas em educação ambiental crítica no futuro. A boa notícia é que não precisamos sair do nosso caminho e fazer enormes esforços para inserir a estética e a afetividade em nossas pesquisas: já estão lá. O esforço necessário é na reorientação do olhar, nesse processo gerando significado sobre a agência do pesquisado pelo pesquisador, enquanto o pesquisador também precisa aumentar seu auto-entendimento sobre como a 
afetividade molda o planejamento, a conduta e a representação de sua pesquisa. Poderíamos até dizer que é só uma questão de unir os olhares e ligar os pontos...

\section{Referências}

ABRAM, D. Merleau-Ponty and the voice of the Earth. In: MACAULEY, D. (Org.). Minding nature. The philosophers of ecology. New York - London: The Guildford Press, 1996.

AGUAYO, C. The use of education for sustainability websites for community education in Chile. 2014, 466p. Tese (PhD in Education). Technology, Environmental Mathematics and Science Educational Research Centre, University of Waikato, Hamilton, New Zealand, 2014.

BALLANTYNE, R.; PACKER, J. Promoting environmentally sustainable attitudes and behavior through free-choice learning experiences: What is the state of the game? Environmental Education Research, v.11, n.3, p.281-295, 2005.

BRASIL. Ministério do Meio Ambiente. Diretoria de Educação Ambiental. Identidades da educação ambiental brasileira. Brasília: MMA, 2004.156 p.

CANAPARO, C. Geo-epistemology: Latin America and the location of knowledge. Oxford: Peter Lang, 2009.

CARVALHO, I. C. M. Epistemologias ecológicas: delimitando um conceito. Mana, v.21, p.163-183, 2014.

CARVALHO, I. C. M. A invenção ecológica: narrativas e trajetórias da Educação Ambiental no Brasil.

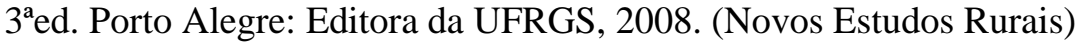

CARVALHO, I. C. M.; STEIL, C. Nature and ecological imagination: the god of ecology within the imaginative horizon of environmentalism. Ambiente \& Sociedade, São Paulo, v.XVI, n.4, p.103-120, 2013.

CARVALHO, L. M. Que educação ambiental desejamos? Ciência em Foco, v.01, p.01-22, 2010.

CHOULIARAKI, L.; FAIRCLOUGH, N. Discourse in late modernity: rethinking Critical Discourse Analysis. Edinburg: Edinburg University Press, 1999.

DELEUZE, G. Le courses de Guilles Deleuze. Spinoza. Cours Vincennes. 24/01/1978. Disponível em: <http://www.webdeleuze.com>. Acesso em: 25 set. 2015.

EICH, E.; SCHOOLER, J. W. Cognition/emotion interactions. In: KIHLSTROM, J. F.; BOWER, G. H.; FORGAS, J. P.; NIEDENTHAL, P. M. (Eds.). Cognition and emotion. Oxford: Oxford University Press. 2000. p.3-29.

FIEN, J. Education for the environment: Critical curriculum theorizing and environmental education. Geeelong, Victoria: Deakin University Press. 1993.

FINCHAM, B.; MCGUINESS, M.; MURRAY, L. (Org.). Mobile methodologies. London: Palgrave Macmillan, 2010.

GRÜN, M. Ética e educação ambiental: a conexão necessária. Campinas: Papirus, 1996. (Coleção Magistério: Formação e Trabalho Pedagógico) 
HART, P. Preconceptions and positionings: Can we see ourselves within our own terrain? In: STEVENSON, R., BRODY, M., DILLON, J., WALS, A. (Org.). International Handbook of Research on Environmental Education. New York: Routledge, 2013. p. 507-511.

HART, P. Transitions in thought and practice: links, divergences and contradictions in post critical inquiry. Environmental Education Research, v.11, n.4, p.391-400, 2005.

HART, P; NOLAN, K. A critical analysis of research in environmental education. Studies in Science Education, v.34, p.1-69, 1999.

HERMANN, N. Ética: a aprendizagem da arte de viver. Revista Educação e Sociedade, v.29, n.102, p.15-32, 2008. Disponível em: <http://www.scielo.br/scielo.php?script=sci_arttext\&pid=S0101$73302008000100002 \& \operatorname{lng}=e n \& n r m=i s o>$. Acesso em: 24 set. 2015.

IARED, V. G. A experiência estética no Cerrado para a formação de valores estéticos e éticos na educação ambiental. 2015, 173p. Tese (Doutorado em Ciências). Centro de Ciências Biológicas e Saúde, Universidade Federal de São Carlos, São Carlos, 2015.

IARED, V. G., OLIVEIRA, H.T.; PAYNE, P.G. The aesthetic experience of nature and hermeneutic phenomenology. The Journal of Environmental Education, v. 47, p. 1-11, 2016

INGOLD, T.; VERGUNST, J.L. (Eds). Ways of walking: ethnography and practice of Foot. Surrey, UK: Ashgate Publishing, 2008.

JACOBI, P. Educação ambiental: o desafio da construção de um pensamento crítico, complexo e reflexivo. Educação e Pesquisa, São Paulo, v.31, n.2, p.233-250, 2005.

JACOBI, P. Educação ambiental, cidadania e sustentabilidade. Cadernos de Pesquisa, n.118, p.189$205,2003$.

JAY, M. Somaesthetics and democracy: Dewey and contemporary body art. Journal of Aesthetics Education, v.6, n.4, p.55-69, 2002.

JULIANI, S. F.; FREIRE, L. M. O papel da extensão universitária na inserção curricular da educação ambiental: uma experiência no curso de ciências Biológicas da UFRJ. Revista de Ensino de Biologia da Associação Brasileira de Ensino de Biologia (SBEnBio), v. 7, p. 6723-6734, 2014.

KUSENBACH, M. Street phenomenology: the go-along as ethnographic research tool. Ethnography, v.4, p. 455- 485, 2003.

LE GRANGE, L. Why we need a language of (environmental) education. In: STEVENSON, R., BRODY, M., DILLON, J., WALS, A. (Org.). International Handbook of Research on Environmental Education. New York: Routledge, 2013. p.115-121.

LORIMER, H. Walking: new forms and spaces for studies of walking. In CRESSWELL, T.; MERRIMAN, P. (eds). Geographies of mobilities: practices, spaces, subjects. Farnham: Ashgate, 2011. p. 19-34.

MARIN, A. A. Pesquisa em educação ambiental e percepção ambiental. Pesquisa em Educação Ambiental, v.3, n.1, p.203-222, 2008.

MARIN, A. A.; OLIVEIRA, L. C. B. A experiência estética em Dufrenne e Quintás e a percepção de natureza: para uma educação ambiental com bases fenomenológicas. REMEA, v.15, p.196-210, 2005. 
McKENZIE, M. et al. Fields of green: restoring culture, environment, and education. Cresskill: Hampton Press, 2009.

MERLEAU-PONTY, M. Fenomenologia da percepção. Rio de Janeiro: Freitas Bastos, 1971.

MERLEAU-PONTY, M. The visible and the invisible. Evanston: Northwestern University Press, 1968.

PAYNE, P. Critical curriculum theory and slow ecopedagogical activism. Australian Journal of Environmental Education, v.32, n.2, p.1-29, 2015.

PAYNE, P. Vagabonding slowly: ecopedagogy, metaphors, figurations, and nomadic ethics. Canadian Journal of Environmental Education, n.19, p.47-69, 2014.

PAYNE, P. G. (Un)timely ecophenomenological framings of environmental education research. In: STEVENSON, R. B. et al. International Handbook of Research on Environmental Education. New York: Routledge Publishers, 2013. p.424-437.

PAYNE, P. Framing research: conceptualization, contextualization, representation and legitimization. Pequisa em Educação Ambiental, v.4, n.2, p.49-77, 2009.

PAYNE, P. 'Ways of doing', learning, teaching and researching. Canadian Journal of Environmental Education, n.10, p.108-124, 2005.

PAYNE, P. Postmodern challenges and modern horizons: education 'for being for the environment' Environmental Education Research, v.5, n.1, p.5-34, 1999.

PAYNE, P.; WATTCHOW, B. Phenomenological deconstruction, slow pedagogy, and the corporeal turn in Wild Environmental/Outdoor Education. Canadian Journal of Environmental Education, v.14, p.15-32, 2009.

PINK, S. Doing sensory ethnography. Los Angeles: Sage, 2009.

REID, A; SCOTT, W. (Org). Researching education and the environment: retrospect and prospect. Environmental Education Research, n.12, v.3-4, p.571-587, 2006.

RICKINSON, M., LUNDHOLM, C., \& HOPWOOD, N. Environmental learning: insights from research into the student experience. Dordrecht, Netherlands: Springer, 2009.

ROBOTTOM, I.; HART, P. Research in environmental education: engaging the debate. Geelong: Deakin University Press, 1993.

RODRIGUES, C. Ecomotricity: considerations on a conceptual framework. In: COLÓQUIO DE PESQUISA QUALITATIVA EM MOTRICIDADE HUMANA: ETNOMOTRICIDADES DO SUL, 6, 2015, Valdivia, Chile. Anais...São Carlos: SPQMH, 2015. CD-ROM. ISSN 1981-7142. p. 371-380.

RODRIGUES, C.; GONÇALVES JUNIOR, L. Ecomotricidade: sinergia entre educação ambiental, motricidade humana e pedagogia dialógica. Motriz, Rio Claro, v.15, n.4, p.987-995, 2009.

RUSSELL, C.; HART, P. Exploring new genres of inquiry in environmental education research. Canadian Journal of Environmental Education, v.8, p.5-8, 2003.

SATO, M.; ISABEL, C. (Org.). Educação ambiental: pesquisa e desafios. Porto Alegre: Artmed, 2008. 
SENICIATO, T.; CAVASSAN, O. Aulas de campo em ambientes naturais e aprendizagem em ciências - um estudo com alunos do ensino fundamental. Ciência e Educação, v.10, n.1, p.133-147, 2004.

SENICIATO, T.; CAVASSAN. O ensino de Ecologia e a experiência estética no ambiente natural: Considerações preliminares. Ciência e Educação, v.15, n.2, p.393-412, 2009.

SORRENTINO, M. et al. Educação ambiental como política pública.Educação e Pesquisa, v.31, n.2, p.285-299, 2005.

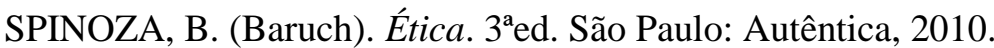

STEVENSON, R. B., BRODY, M., DILLON, J., WALS. A. (Org). International Handbook of Research on Environmental Education. New York: Routledge Publishers, 2013,

THOMAS, K. O homem e o mundo natural: mudança de atitude em relação às plantas e aos animais, 1500-1800. São Paulo: Companhia das Letras, 1988.

THRIFT, N. Non-representational theory: space politics affect. London: Routledge, 2008.

TOADVINE, T. Merleau-Ponty's philosophy of nature. Evanston, IL: Northwestern University Press, 2009.

TOZONI-REIS, M. F. C. Contribuições para uma pedagogia crítica da Educação Ambiental: reflexões teóricas. In: LOUREIRO, C. F. (Org.). A questão ambiental no pensamento crítico: natureza, trabalho e educação. Rio de Janeiro: QUARTET, 2007. 